\title{
Competência ética do bibliotecário: um fator de qualidade
}

\author{
Mariana Giubertti Guedes ${ }^{1}$ \\ Sofia Galvão Baptista ${ }^{2}$ \\ Maria Alice Guimarães Borges ${ }^{3}$
}

Resumo: A importância do entendimento das normas éticas que regem o profissional da informação, a competência ética que o capacita para exercer sua profissão com excelência e a influência da conduta bibliotecária em relação à qualidade de serviço prestado são discutidas.

Palavras chaves: profissional da informação; ética, conduta do bibliotecário e qualidade de serviço

Abstract: The importance the ethical rules understanding and the importance of ethical competence that enables him to do his job with excellence are discussed, as well as the ethical rules influence on librarian conduct in relation to quality of service.

Key words: information professional ethical rules; information society, librarian conduct; quality service; library service

Resumen - En este artículo se discute la ética de la información profesional. La importancia de comprender las normas éticas que rigen su profesión y, asimismo, la importancia de la competencia ética que le permite hacer su trabajo con excelencia. Discute la influencia de la conducta bibliotecario en relación con la calidad del servicio. En relación con la sociedad de la información y sus normas de conducta y servicios de la biblioteca, la competencia de la ética profesional de la información se convierte en esencial.

Palabras claves: normas de conducta, sociedad de la información, trabajador de la información - la ética, la calidad del servicio - biblioteca.

\footnotetext{
${ }^{1}$ Aluna do mestrado no Programa de Pós-Graduação em Ciência da Informação da Universidade de Brasília (UnB); e-mail: mari_biblio@hotmail.com

${ }^{2}$ Professora (UnB) doutora em Ciência da Informação, líder do grupo de pesquisa sobre o profissional; email: sofiag@unb.br

${ }^{3}$ Professora (UnB) doutora em Ciência da Informação e orientadora; e-mail: malice@unb.br 
... para determinar a missão do bibliotecário, é preciso partir não só do homem que a exerce, de seus gostos, curiosidades ou conveniências, tampouco de um ideal abstrato que pretendesse definir de uma vez por todas o que é uma biblioteca, mas da necessidade social a que serve vossa profissão.

José Ortega y Gasset

\section{Introdução}

Na Sociedade da Informação, a informação se torna parte integrante da produção. Aqueles que sabem lidar com esta nova realidade possuem uma vantagem frente aos seus semelhantes. As empresas, por exemplo, já incluem a informação e o conhecimento dentre seus recursos essenciais, pois sua sobrevivência no mercado depende deles. Outra mudança significativa que surgiu desta sociedade foi o reconhecimento do trabalho intelectual do profissional dentro das empresas, as qualificações se transformaram em competências.

Dentre várias competências, a competência informacional é o conjunto de competências profissionais, organizacionais e competências-chave que possa estar ligada ao perfil de um profissional da informação ou de uma atividade baseada intensivamente em informação (MIRANDA, 2004). O desenvolvimento da competência informacional em um profissional da informação surge, dentre outras motivações, para suprir as necessidades informacionais do usuário, aprimorando seu trabalho de mediador da informação. Mas a competência informacional não é restrita ao profissional da informação.

A capacidade de transformar aprendizagem e conhecimento em competências é retratada como enfoque na aprendizagem organizacional, em especial a competência essencial da empresa. As competências informacionais aos poucos se tornam realidade nas empresas, vê-se o número cada vez maior de mestres e doutores em Ciência da Informação, de outras áreas, não só para o aprendizado, mas também para implantar estratégias informacionais em seus ambientes de trabalho e em suas áreas de atuação. Para Farias e Cunha (2009), o profissional não se limita à formação 
profissional, deve, portanto trabalhar suas habilidades para enfrentar diversas situações.

Toda profissão é regida por uma norma de conduta, valores que determinam o seu exercício. Para o profissional da informação uma questão muito discutida é a ética relacionada à manipulação da informação. Os profissionais da informação, em geral, têm objetivos comuns, pois em suas prestações de serviços identificam informações desejadas pelos usuários e de alguma forma buscam suprir tais necessidades dos usuários.

A informação é um objeto que levanta diversas questões sociais, econômicas, tecnológicas e políticas e científicas, "a expansão dos suportes materiais e virtuais de informação tem levado ao aparecimento de formas organizacionais distintas e ao estabelecimento de novas relações entre os indivíduos" (JAMBEIRO; SILVA, p. 4, 2004). Para Barreto (1999 apud JAMEIRO; SILVA, 2004) na sociedade da informação há os fenômenos de interatividade e interconectividade e, estas modificam os papéis dos profissionais da informação e transformam a relação do usuário e da informação. Sendo assim, o profissional da informação deve estar em constante atualização, ser um sujeito com qualidades adaptativas, informacionais e políticas.

A qualidade em unidades de informação se baseia no cumprimento de seus serviços, seria possível afirmar que em uma biblioteca, seu lucro é a satisfação do usuário ao atender conforme sua expectativa tanto de seus serviços como de seus produtos, porém é fundamental neste ambiente ter profissionais motivados que exerçam bem suas funções "[...] as pessoas são mais importantes, a tecnologia é secundária para a qualidade em serviços." (SILVA, 2002, p. 23).

O bibliotecário tem competências essenciais para exercer sua profissão com excelência, e dentre estas a competência ética. Seria correto afirmar que a competência ética do bibliotecário é um diferencial na qualidade de serviços e produtos oferecidos pela unidade de informação em que trabalha? 


\section{Competências do profissional da informação na sociedade da informação}

Antes de abordar sobre a competência ética em profissionais da informação é necessário primeiro entender a sua atuação na sociedade e o seu objeto dentro desta dinâmica social.

A Sociedade da Informação surgiu da mudança de paradigma em relação à informação, que teve seu aumento considerável, e ao ingresso de tecnologias da informação e comunicação, segundo Brasil (2000, p.5): “[...] a sociedade da informação não é um modismo. Esse novo paradigma representa uma profunda mudança na organização da sociedade e da economia, havendo quem a considere um novo paradigma técnico-econômico".

No Quadro 1, Borges (2000) compara a situação das organização nos dois contextos: a sociedade industrial e a sociedade da informação e do conhecimento. $\mathrm{Na}$ Sociedade da Informação, há a valorização da informação somada aos benefícios tecnológicos. A informação se torna um produto tendo importância econômica e a tecnologia cria uma nova realidade no processo comunicativo. Neste contexto, as estruturas organizacionais se adaptam tanto no enfoque operacional, econômico, social e tecnológico.

Quadro 1-Quadro comparativo

\begin{tabular}{|c|c|}
\hline EMPRESA DA SOCIEDADE INDUSTRIAL & $\begin{array}{l}\text { EMPRESA DA SOCIEDADE DA } \\
\text { INFORMAÇÃO }\end{array}$ \\
\hline Enfoque analítico/atomístico & Enfoque macro/holístico \\
\hline $\begin{array}{l}\text { Individualismo/predomínio/distanciamento } \\
\text { entre as pessoas }\end{array}$ & $\begin{array}{c}\text { Igualdade de } \\
\text { direitos/compartilhamento/participação }\end{array}$ \\
\hline $\begin{array}{c}\text { Autoridade } \\
\text { centralizadora/paternalista/autocrática }\end{array}$ & Autoridade adulta/facilitadora/democrática \\
\hline $\begin{array}{c}\text { Continuidade num único nicho profissional } \\
\text { Especialização excessiva }\end{array}$ & $\begin{array}{l}\text { Opções múltiplas } \\
\text { Liberdade de escolha } \\
\text { Visão generalizada }\end{array}$ \\
\hline $\begin{array}{l}\text { Economia de escala/tendência ao gigantismo } \\
\text { e à centralização }\end{array}$ & Descentralização, resguardando-se a integração \\
\hline Valorização da quantidade & $\begin{array}{l}\text { Valorização da qualidade associada à } \\
\text { quantidade }\end{array}$ \\
\hline
\end{tabular}




\begin{tabular}{|c|c|}
\hline $\begin{array}{c}\text { Empresário avesso ao risco } \\
\text { Busca de protecionismo }\end{array}$ & $\begin{array}{c}\text { Empresário empreendedor, criativo e } \\
\text { competitivo }\end{array}$ \\
\hline A grande alavanca é o dinheiro & $\begin{array}{c}\text { A grande alavanca é a informação/o } \\
\text { conhecimento/a educação }\end{array}$ \\
\hline $\begin{array}{c}\text { O sucesso é garantido pelo poder de } \\
\text { investimento em máquinas e instalações }\end{array}$ & $\begin{array}{c}\text { A mente humana é o grande software } \\
\text { O computador é o grande hardware }\end{array}$ \\
\hline
\end{tabular}

Fonte: Borges, 2000, p.29

Esta nova ordem social é baseada na rapidez e flexibilidade, além de exigir mais serviços do que produtos. Para Freire et al (2009, p47), o mercado, no qual as empresas estão inseridas, é marcado por uma competição acirrada e constantes mudanças, o que impõe a necessidade de contínua adequação às novas regras do mercado". (FREIRE et al, 2009, p.4).

Santos e Carvalho (2009, p.47) defendem:

O ideal é que a Sociedade da Informação possa gerar e criar um complexo de relações focado na informação, tendo como pano de fundo a criação de políticas públicas que contribuam para a diminuição da exclusão de milhares de pessoas que não possuem acesso às tecnologias da informação e comunicação por meio da valorização da produção, distribuição e assimilação de conteúdos que possam ter impacto no dia-a-dia do cidadão, assim além da conectividade os programas poderiam criar coletivos inteligentes e produtores de conteúdo.

O livro Sociedade da Informação no Brasil: Livro Verde (BRASIL, 2000) traz uma proposta de implantação da Sociedade da Informação no Brasil. Dentre os problemas para a implantação deste processo no país, destaca-se a educação continuada, que deve capacitar o indivíduo não apenas para acompanhar as mudanças tecnológicas, como também para saber inovar.

Na Pesquisa Nacional por Amostra de Domicílios do Instituto Brasileiro de Geografia e Estatística (BRASIL, 2010), concluiu-se que a taxa de analfabetismo caiu entre 2004 e 2009, entretanto, no ano passado ainda existiam no Brasil 14,1 milhões de analfabetos. Dentro desta realidade surge o desafio de superar antigas deficiências educacionais e criar as competências requeridas pela nova economia. E uma competência essencial, para o profissional desta sociedade, é transformar conhecimento em informação. 
Na sociedade da informação, a inclusão de tecnologias modifica a dinâmica do fluxo informacional. Para Jambeiro e Silva $(2004$, p.4) o auxílio da tecnologia permite que mais pessoas tenham acesso à informação em menos tempo, dinamizando os processos informacionais na sociedade atual, menos energia humana é gasta a cada dia para manipular materiais usados na produção de bens e serviços. A informação torna-se o instrumento pelo qual os processos, funções e colaboradores são direcionados para uma flexibilidade e capacidade de adaptação às novas regras do mercado, sendo assim, a manipulação da informação é uma das problemáticas de vários profissionais.

Dentre os diversos profissionais da informação, destaca-se o trabalho do bibliotecário que tem como atribuição registrar, processar, armazenar, pesquisar, recuperar e disseminar ou comunicar informações (MARCHIORI; PACHECO, 1997; p.5657). Tal profissional, ao lidar com a informação neste novo parâmetro social, deve não só se preocupar com a preservação da cultura humana, mas também com a forma de utilização, disseminação, recuperação, acesso e uso, independente do suporte em que está registrada.

As autoras descrevem quem são os profissionais e quais são as suas tarefas, a saber:

(a) Identificar o tipo de informação desejado pelos usuários/clientes (b) identificar a "natureza" dessa demanda de informação, incrementando modelos e/ou serviços e/ou produtos (produção, coleta, análise, tratamento, organização, etc.) que venham resolver o "problema" de informação do usuário/cliente a curto, médio ou longo prazo;

(b) identificar como esses modelos devem ser operados de modo a resultar em serviços de qualidade, racionalizando investimentos e incrementando os benefícios

O mercado de trabalho no contexto da Sociedade da Informação exige dos profissionais novas competências, habilidades e adaptabilidade para acompanhar a dinâmica tecnológica e informacional. Ferreira (2003) questiona quais seriam as habilidades do profissional da informação para suprir a demanda atual do mercado. A autora afirma que os profissionais da informação são essenciais para o funcionamento 
de organizações do conhecimento, pois permite que a informação se torne uma vantagem competitiva nas mesmas, para isso é necessário que o profissional tenha uma combinação de "conhecimentos técnico-profissionais e conhecimentos pessoais" além de "atitudes comportamentais, como comunicação social e pessoal" (FERREIRA, 2003, p.46).

Aranalde (2005) destaca uma nova realidade cultural, onde a cultura escrita cede lugar à cultura digital. Nesta realidade, o bibliotecário deve se adaptar a esta nova exigência do mercado, desenvolvendo novas competências, responsabilidades e habilidades.

A cultura digital cria imperativos de adaptabilidade e de capacidade de transformação e enfatiza um começar de novo a cada instante. Tal cultura tem como conseqüência a característica mais marcante da sociedade de informação, a saber, a ausência de comprometimento a longo prazo. Assim, temos que a rapidez e a flexibilidade acabam ultrapassando os limites de sua aplicação ao campo da tecnologia, sendo inseridas como imperativos de ação. Desse modo, mesmo no âmbito das relações humanas, a flexibilidade é a nova ordem frente à rapidez com que as mudanças se processam. Entretanto, isso é um caminho de duas vias, pois a exigência por flexibilidade acaba acelerando os processos de mudança. (ARANALDE, 2005, p. 342)

Do ponto de vista formal, a CBO (Classificação Brasileira de Ocupações - MCT) descreve as características das ocupações do mercado de trabalho brasileiro, nela são citadas as competências dos profissionais da informação, como demonstrado no Quadro 2.

Quadro 2 - Competências do profissional da informação e suas correspondências no núcleo de competências exigidas pelas organizações

\begin{tabular}{|c|l|l|}
\hline & $\begin{array}{c}\text { Competências do profissional da informação na } \\
\text { Classificação Brasileira de Ocupações }\end{array}$ & $\begin{array}{c}\text { Competências requeridas } \\
\text { pelas organizações }\end{array}$ \\
\hline 1 & Manter-se atualizado & Disposição para mudanças \\
\hline 2 & Liderar equipes & Liderança \\
\hline 3 & Trabalhar em equipe e em rede & Afetividade + sociabilidade \\
\hline 4 & Demonstrar capacidade de análise e síntese & Análise e síntese / ou avaliação \\
\hline 5 & Demonstrar capacidade de outros idiomas & Comunicação \\
\hline 6 & Demonstrar capacidade de comunicação & Comunicação \\
\hline 7 & Demonstrar capacidade de negociação & Negociação \\
\hline 8 & Agir com ética & Ética ou liderança \\
\hline 9 & Demonstrar senso de organização & Organização e planejamento \\
\hline 10 & Demonstrar capacidade empreendedora & Realização \\
\hline
\end{tabular}


ARTIGOS

\begin{tabular}{|c|l|l|}
\hline 11 & Demonstrar raciocínio lógico & $\begin{array}{l}\text { Criatividade + outras capacidades } \\
\text { cognitivas }\end{array}$ \\
\hline 12 & Demonstrar capacidade de concentração & Atenção / priorização \\
\hline 13 & Demonstrar pro atividade & Antecipar ameaças \\
\hline 14 & Demonstrar criatividade & Flexibilidade / criatividade \\
\hline
\end{tabular}

Fonte: FARIA et al, 2005, p.30.

Dentre as competências do profissional da informação, vê-se que ele deve "agir com ética", ou seja, a preocupação ética é uma exigência profissional e em algumas vezes até associada à liderança dependendo da empresa. Isso demonstra que as organizações têm desenvolvido mapeamento de competências como uma ferramenta estratégica, analisado valores organizacionais e profissionais para a vantagem competitiva.

\section{1 Ética profissional}

A ética é a ciência da conduta humana. Litton (1970, p.177) define a ética como "um conjunto de normas de conduta aplicadas a qualquer situação em que se encontra o homem; é a ciência prática que dirige, com a simples razão natural, os atos humanos ao bem individual e social". No entanto não é uma verdade fixa, durante os tempos, a ética vai se modificando de acordo com a influência cultural.

Ética e moral, apesar de muitas vezes serem consideradas sinônimos, não têm o mesmo significado. A moral é um conjunto de regras de conduta admitidas em determinada época ou por um grupo de pessoas enquanto que ética (ou filosofia da moral) se ocupa com a reflexão a respeito das noções e princípios que fundamentam a vida moral (ARANHA; MARTINS, 2003). A ética, portanto, tem a moral como seu objeto. A ética espelha a busca do equilíbrio entre o comportamento humano, suas ações e seu ambiente. A sociedade é diretamente associada às questões éticas, pois reflete a atuação do homem após reflexão moral. Tal reflexão implica tanto a razão como também sentimentos humanos. O ser humano está em constante questionamento sobre o bem e o mal, o certo ou o errado.

Tavares (1986 apud RASCHE, 2005, p.38) define a ética como 
[...] um sistema de normas, princípios e valores, segundo o qual são regulamentadas as relações mútuas entre os indivíduos ou entre estes e as comunidades, de tal maneira que estas normas, dotadas de um caráter histórico e social, sejam acatadas livremente e conscientemente, por uma convicção íntima e não de uma maneira mecânica, externa ou impessoal.

As regras têm um importante papel em qualquer sociedade, pois ele determina os limites e possibilidades que o indivíduo deve se submeter, auxiliando-o em tomada de decisões frente a dilemas da vida. Tais normas são consideradas, por muitos, como valores morais (MISCHIATI; VALENTIM, 2005). O trabalho profissional se origina de necessidades sentidas por toda a sociedade, grupos dentro dela, ou indivíduos isolados (ABBOTT, 1988 apud MUELLER, 2004, p.31), sendo assim, o profissional da informação tem um papel social e, como tal, deve se preocupar com as suas ações, pois a responsabilidade social é baseada na ética, que se fundamenta no bem comum. Fernandéz-Molina (2009) analisa os aspectos éticos presentes no exercício da profissão bibliotecária. O autor afirma que as principais áreas com implicações éticas para o bibliotecário são: seleção de documentos, o acesso à informação, o serviço de referência, a confidencialidade dos dados pessoais e o direito autoral. Nestes setores é normal se deparar com situações em que terá de tomar decisões, e estas ações muitas vezes determinam o cumprimento de atividades essenciais para a organização. A questão é: o bibliotecário tomará decisões éticas?

No dia a dia, o bibliotecário lida com um sistema na qual ele é um agente essencial para que este alcance seus objetivos, que é atender a demanda informacional do usuário. Por isso a sua conduta influencia toda uma organização viva e dinâmica. É fundamental que este profissional enfrente todos os conflitos e problemas que ocorra na execução de suas tarefas, e que também deva levar em consideração o social, evitando tomar decisões baseado no bem próprio.

De acordo com Sá (1996), há várias vertentes na ética profissional, podendo ser em relação ao cliente, ao colega, a classe e a remuneração. As condutas neste sentido podem variar dependendo do caráter da pessoa, mas é também relevante ressaltar que as pessoas estão em constante transformação e aprendizado, as reflexões éticas e ações resultantes muitas vezes são determinadas pelas diversas experiências 
acumuladas ao longo da profissão. O conjunto de princípios e normas que um grupo estabelece para seu exercício profissional é outra vertente da ética, a ética profissional que geralmente se institucionaliza como código de ética. O código de ética do bibliotecário surgiu em 1966, na "Primeira Reunião Plenária do Conselho Federal de Biblioteconomia", ratificado através da Resolução no 005/66, sendo reformulado e aprovado através da Resolução no 327186 (CONSELHO FEDERAL DE BIBLIOTECONOMIA 1a REGIÃO, 2009). De acordo a Resolução acima, o código de é formado de um conjunto de políticas que abrange as questões relacionadas à profissão, como a relação do profissional com os usuários, as atividades, colegas e a classe, além de recomendações, proibições e penalidades. Ele se divide nas seguintes seções:
I. Objetivos
II. Deveres e obrigações
III. Dos direitos
IV. Das proibições
V. Das infrações disciplinares e penalidades
VI. Da aplicação de sanções
VII. Dos honorários profissionais
VIII. Das disposições gerais

O código de ética é um referencial, um parâmetro para auxiliar o profissional a tomar decisões e cumprir seu papel social, tendo a premissa que o bibliotecário tem como fundamento profissional atender a sociedade. Porém ter um código de ética como referencial não exclui a necessidade do bibliotecário ter uma competência ética.

\subsection{Competências éticas}

Para entender a dimensão da competência ética, é necessário primeiramente introduzir o conceito de competência. Para Vitorino (2007, p.61)

[...] um conceito básico de competência é uma capacidade de agir eficazmente em um tipo de situação, capacidade esta que se apóia em conhecimentos, mas não se reduz a eles, pois as competências utilizam, integram, mobilizam conhecimentos para enfrentar um conjunto de situações complexas e o mais importante: implicam também em uma capacidade de atualização de saberes. 
As competências proporcionam às empresas uma vantagem estratégica, pois mantêm alto nível de eficiência, resultando qualidade de seus serviços e produtos. Não há consenso na classificação de competências, elas podem ser classificadas como: comportamentais, pessoais, diferenciadora, individuais, específicas, entre outras. Chiavenato (2005, p.205) as divide em dois grupos: técnicas e humanas. No Quadro 3, pode-se visualizar como estas competências se relacionam com as necessidades da organização.

Quadro 3 - Tipos de competências

\begin{tabular}{|l|l|l|l|}
\hline $\begin{array}{c}\text { Tipos de } \\
\text { Competências }\end{array}$ & $\begin{array}{c}\text { Habilidades que a } \\
\text { organização já possui }\end{array}$ & $\begin{array}{l}\text { Mudanças que ocorrem } \\
\text { no negócio organização }\end{array}$ & $\begin{array}{l}\text { Habilidades de que a } \\
\text { organização necessita }\end{array}$ \\
\hline Técnicas & Qualidade & Excelência & Perfeccionismo \\
& Produtividade & Competição & Competitividade \\
& Ruptuativadade \\
\hline Humanasas & Confiabilidade & Espírito empreendedor & Participação \\
& Relações humanas & Parcerias & Engajamento \\
& Respeito mútuo & Ética & Comportamento ético \\
& Iniciativa pessoal & Responsabilidade social & Atitude responsável \\
\hline
\end{tabular}

Fonte: CHIAVENATO, 2005 apud CAMPOS; HOKAYEN-DA-SILVA; ROSVADOSKI, 2008, p.6.

Para entender melhor a competência ética, ela será relacionada com tipos de competências variadas para determinar seu conceito. Estas classificações foram baseadas em Miranda (2004). A competência ética se fundamenta em:

- Competência interpessoal - comportamento humano em relações interpessoais, lida com a sensibilidade social e empatia.

- Competência individual - Conhecimento, especialidades e experiências, aqueles ligados à cognição da pessoa.

- Competência social (inclusa na competência individual) - é ligada a interação com pessoas.

- Competência organizacional - são processos que permitem combinar aptidões, sistemas ativos e valores, proporcionando vantagem competitiva, é baseado na questão estratégica. 
- Competências de fundo - á aquele adquirido em situação educativa, formalizada em conquistas cognitivas e comportamentais necessárias para enfrentar as categorias de situação-problema.

Para o bibliotecário é essencial obter competência informacional. Esta, por sua vez, obtém três dimensões que se relacionam também com a competência ética. De acordo com Miranda (2006), estas três dimensões seriam: o saber (conhecimento), saber-fazer (habilidades) e saber-agir (atitudes).

Para Miranda (2006, p.109):

As dimensões da competência informacional podem ser exemplificadas como: 1) conhecimentos sobre a arquitetura e o ciclo da informação; como obter produtos e serviços de informação; como selecionar fontes, canais, contextos e tecnologias adequados de informação para solucionar problemas específicos de usuários de informação específicos; 2) habilidades de detectar necessidades; avaliar o custo/benefício da busca e uso da informação para solucionar problemas; lidar com a $\mathrm{Tl}$; 3) atitudes de integridade, controle e compartilhamento, transparência, proatividade - uma "cultura informacional" rica e positiva capaz de avaliar o valor da informação para cada usuário no intuito de atender suas necessidades. O que especifica conhecimentos, habilidades $\mathrm{e}$ atitudes de um usuário que desenvolve a competência informacional é a sua eficiência e efetividade em reconhecer suas necessidades de informação e atendê-las para cumprir objetivos em suas tarefas e resolver seus problemas informacionais.

Miranda (2007) estrutura as dimensões (saber, saber-fazer e saber agir) e os elementos das competências informacionais na Figura 1, demonstrando o contexto de uma forma didática, porém ressalta "que essas dimensões são didáticas, sua identificação na realidade é difícil dada a interconexão existente entre elas" (MIRANDA, 2007, p.113). 


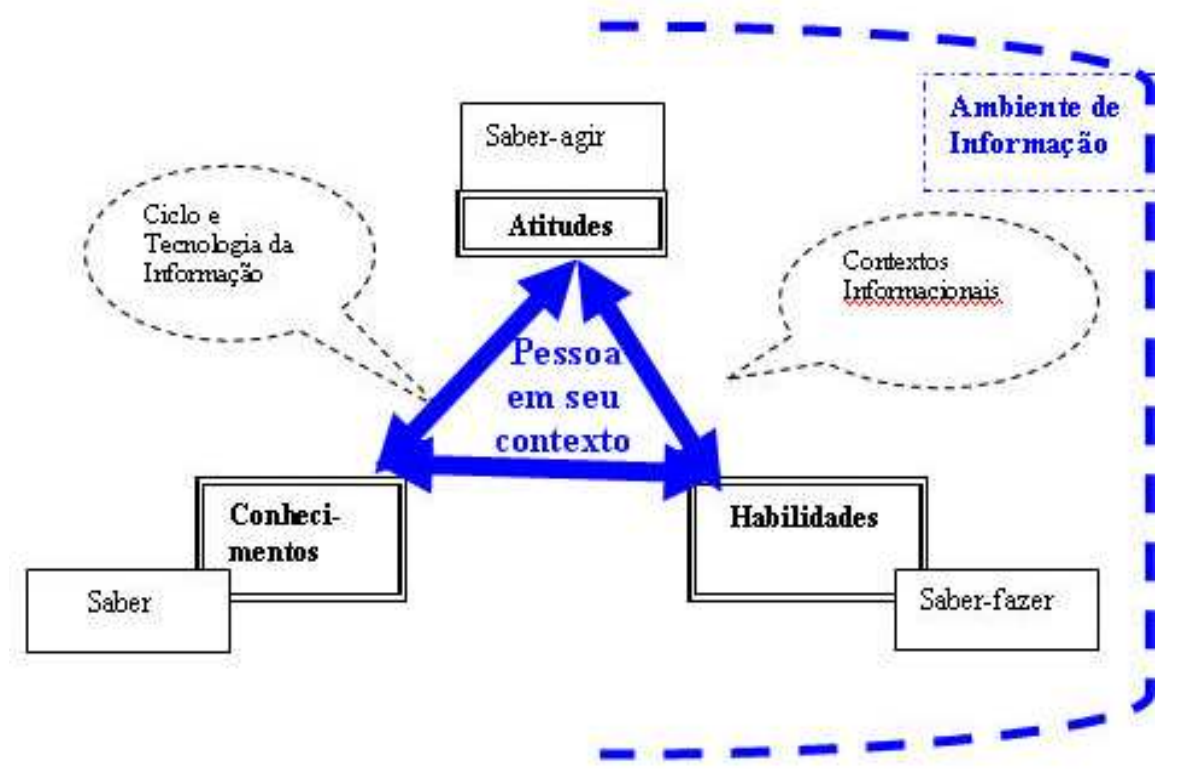

Fonte: Miranda, 2007, p.113

Figura 1 - As dimensões e os Elementos das Competências informacionais

De certa forma, podemos observar que estes três aspectos se relacionam com a ética. O saber é a inteligência intuitiva, incluindo também os valores da pessoa, todo o conhecimento resultado de aprendizados e experiências. O saber-fazer se fundamenta na ação, a capacidade de aplicar o saber e o saber-agir é todo aspecto social que condiciona um comportamento, o processo de resolução de problemas. Todas estas dimensões se interligam, envolvendo a ética do pensar ao agir (MIRANDA, 2007, p.113).

Para uma pessoa ser capaz de tomar decisões éticas, ela necessita ter alguns valores fundamentais como: honestidade; respeito ao indivíduo; coragem; tolerância; integridade; flexibilidade; caráter sigiloso; humildade; responsabilidade, entre outros. Esses valores permitem que o indivíduo tenha uma decisão sensata voltada para 0 bem social, em vez do próprio, trazendo um balanço positivo ao sistema em que está, no caso, a organização em que trabalha. Assim, o profissional da informação que lida com o ciclo informacional, também será necessário obter uma competência ética, pois todo o processo está estritamente ligado ao sucesso da prestação de serviços de uma unidade de informação e a eficácia é fundamental, abaixo na Figura 2, vê-se o processo. 


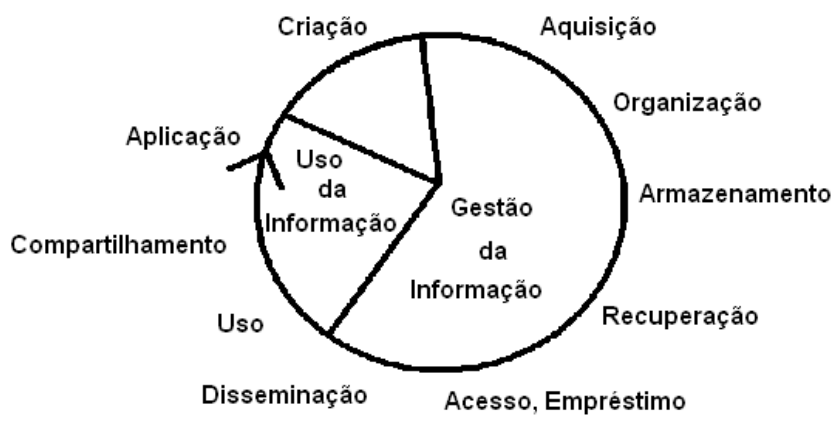

Fonte: Suaiden, 2006.

Figura 2 - O ciclo de vida da Informação estendido

Em todo o processo do ciclo informacional, o bibliotecário está presente, mas como este profissional pode trazer prejuízo para a organização se não conter uma competência ética? No momento de Seleção e Aquisição, o bibliotecário precisa ter princípios éticos que o auxiliem nesta atividade, sempre visando a necessidade de informação do usuário e não a própria, por isso deve-se ter uma política de seleção bem definida.

Nos processos de Organização e Armazenamento, o bibliotecário deve ter a preocupação quanto à integridade da informação e também para com o acesso a ela. Os processos acima exigem um cuidado maior na utilização de alguns tipos de documentos das coleções especiais, o processamento da informação de forma que o usuário encontre-a, disponibilização, quando possível, do documento em outros meios, sempre visando cumprir sua responsabilidade social.

Nas atividades técnicas, que incluem os processos acima (seleção, aquisição, organização e armazenamento), o bibliotecário lida com alguns conflitos tanto da administração quanto com colegas, pois as formas de executá-las são diversas, sendo necessário tomar decisões éticas frente a situações-problema. O código de ética do bibliotecário pode auxiliar nestas circunstâncias.

O profissional que faz o serviço de referência tem um papel essencial na unidade de informação, pois é aquele que tem contato com o usuário. Os processos de Recuperação, Acesso, Empréstimo e Disseminação, se bem executado, atestam todo o trabalho realizado até então, confirmando que o sistema está funcionando. $O$ serviço 
de pesquisa e auxílio ao usuário requer do profissional um comportamento ético, uma vez que lida com pessoas e esta relação bibliotecário/usuário, geralmente, determina a aceitação do usuário.

Outra questão é qual informação disponibilizar ao usuário, por exemplo, em uma biblioteca escolar, se um estudante visivelmente deprimido solicita a(ao) bibliotecária(o) um livro sobre suicídio, como proceder? Este exemplo dado por Fernandéz-Molina (2009), se enquadra bem nas situações que o bibliotecário de referência lida.

Uma competência ética independente do serviço que o bibliotecário executa é essencial para que a biblioteca alcance seus objetivos e metas.

\subsection{Competência ética do bibliotecário e a qualidade}

A ética está relacionada com os valores adquiridos no processo de interação social. O termo qualidade não tem um consenso quanto a sua conceituação, pois há várias discordâncias importantes impossibilitando um entendimento único (GARVIN, 1992).

Ao falar de qualidade, normalmente vem à mente idéias como: trabalho bem feito, busca da perfeição, fator humano, motivação, objetivos, realização pessoal, atendimento de necessidades etc. Estes termos invariavelmente entram nas definições de qualidade fornecidas pelos especialistas e na elaboração da Missão por parte das empresas (CERQUINHO, 2009, p.3).

Há autores, como Silva e Silva (1999) que entendem que o trabalho conjunto de qualidade e ética é no mínimo uma ambigüidade. As empresas podem associar qualidade a lucro, porém para uma biblioteca, a qualidade resultaria em excelência na prestação de serviços que conseqüentemente satisfizessem as necessidades informacionais de seus usuários, sendo assim, neste ambiente a qualidade está inerente à ética.

A relação da ética e da qualidade de serviços estaria na resolução de problemas, ou seja, decisões tomadas que foram baseadas no princípio do bem comum. Atitudes 
antiéticas podem auxiliar a obter resultados, porém se os clientes descobrem estas atitudes a empresa perde sua credibilidade no mercado.

As instituições são formadas por pessoas, Sertek (2009, p.2) defende que “ações valiosas, as de caráter ético dão solidez às pessoas e empresas. Quando se pretende melhoria de qualidade em serviços e produtos o caminho está no cultivo de atitudes éticas". O ambiente muitas vezes condiciona o agir das pessoas e vice-versa, agir é o resultado da tomada de decisões, as decisões se baseiam em reflexões cognitivas (conhecimento, experiências e valores), uma característica individual.

Se profissionais firmarem ações antiéticas em seus ambientes de trabalho, dificilmente esta realidade será modificada e os frutos desta ação serão a ineficiência dos serviços prestados, e assim perde-se qualidade. Segundo Garvin (1992) é possível identificar oito dimensões ou categorias da qualidade para análise: desempenho, características, confiabilidade, durabilidade, atendimento, estética e qualidade percebida. Porém Silva (2002) defende que para uma empresa de serviço, como uma biblioteca, as dimensões seriam: competência (atividades técnicas), atendimento (todas as atividades relacionadas ao usuário), estética (aparência do espaço físico da biblioteca), conforto (Estrutura física, iluminação e conforto térmico) e qualidade percebida (imagem expressa na opinião dos usuários).

A qualidade nos serviços bibliotecários pode se constituir de duas maneiras, aquela adquirida por si mesma e aquela obtida como conseqüência de uma gestão de qualidade. Cada vez mais as bibliotecas buscam uma certificação de qualidade para mensurar as atividades realizadas, seus serviços e produtos e a satisfação dos usuários. Para Gomes Filho (2002), há três componentes que um programa de qualidade deve enfocar para alcançar sucesso: atitudes dos funcionários, percepções dos usuários e gerenciamento do processo.

Aranalde (2005, p.343-344) afirma que

Qualquer relação profissional está fundamentada num conjunto de crenças e práticas compartilhadas. [...] O processo de trabalho sustenta a estrutura social existente, e as transformações nas formas do trabalho afetaram a sociedade como um todo, sendo assim, para uma pessoa ser capaz de tomar decisões éticas, ela necessita ter alguns valores fundamentais que permitem que o indivíduo tenha uma decisão sensata voltada para o bem social, em vez do próprio. 
Neste contexto, Aranalde (2005, p.345) defende que "o caráter de uma pessoa depende de suas ligações com o mundo e com a noção compartilhada de ser necessário aos outros".

Ao se considerar as competências éticas para o bibliotecário (FARIA, 2005), percebe-se a relação dessas competências com o ciclo informacional e a prestação de serviços. Em cada parte do ciclo informacional, existe a preocupação com a busca e entrega da informação correta para usuário, que pode estar na aquisição, na organização e armazenamento ou na recuperação.

A competência ética do profissional está inerente ao fazer bem, baseado em ações fundamentadas em valores morais e sociais. Tal competência prioriza a execução de atividades com excelência permitindo o usuário a satisfação de suas necessidades informacionais, além de transformar a biblioteca num ambiente social agradável de sabedoria e lazer.

\section{Considerações finais}

Os profissionais da informação lidam com situações, em seu local de trabalho, que englobam diversos sistemas, informacionais e de pessoas. A competência ética auxilia o profissional a tomar decisões que geram ações favoráveis à sobrevivência da organização além de passar ao usuário confiança, resultando em prestígio frente à sociedade.

Muitas são as problemáticas que o bibliotecário lida, como por exemplo, o acesso à informação, informações privadas, cópias, direitos autorais, impaciência e intolerância de usuários, prioridade de atendimento, hierarquia de usuários, conflito em relação às atividades exercidas, preservação de materiais informacionais, poucos recursos para biblioteca, serviços mal feitos, colegas desmotivados, entre outros.

Como o bibliotecário pode proceder para que a biblioteca obtenha qualidade em seus serviços? Para Rache (2005 p.79):

a ética profissional bibliotecária pode ser discutida tanto no âmbito do atendimento de serviços a outrem, na relação entre os colegas, na 
relação do que representa seu corpo de conhecimento e de competências para a sociedade e ainda na sua relação com o Estado.

Alguns procedimentos são essenciais para o bibliotecário agir com ética, são eles: conviver bem com seus colegas, estar bem resolvido profissionalmente, não trazer sentimentos inadequados ao seu ambiente de trabalho, reconhecer sua responsabilidade social, executar as atividades técnicas (seleção, aquisição, classificação, catalogação, entre outros) sempre visando as necessidades informacionais dos usuários, atendimento realizado com calma e sabedoria, auxílio aos usuários, cuidado ao lidar com dados pessoais dos usuários, criação de atividades que permita o usuário mais intimidade com a biblioteca, tolerância, criatividade, motivação, esforço pessoal e profissional para que a biblioteca seja sempre uma organização dinâmica e adaptativa.

As empresas, geralmente, buscam uma certificação de qualidade para se estabelecer no mercado. No caso das bibliotecas brasileiras, a competitiva é quase inexistente, pois na sua maioria as bibliotecas estão associadas a uma instituição, 67 privada ou pública. Walter (2005) mostra o exemplo da Biblioteca Ministro Victor Nunes Leal do Supremo Tribunal Federal, que buscou um certificado de qualidade em seus serviços especializados em atendimento a necessidades de informação de usuários internos e externos referentes às pesquisas de doutrina jurídica e de legislação.

As bibliotecas têm como objetivo e meta oferecer ao usuário o melhor de seus serviços. A competência ética do bibliotecário pode se tornar um fator de qualidade em serviços, sendo um agente ativo no sistema, tem suas ações como diferencial no processo de lidar com a informação e levá-la ao usuário. 


\section{Referências}

ARANALDE, Michel Maya. A questão ética na atuação do profissional bibliotecário. Em Questão, Porto Alegre, v. 11, n. 2, p. 337-368, jul./dez. 2005.

ASSOCIAÇÃO BRASILEIRA DE NORMAS TÉCNICAS. NBR 6022: informação e documentação: artigo em publicação periódica científica impressa: apresentação. Rio de Janeiro, 2003. 5 p.

. NBR 6023: informação e documentação: referência: elaboração, 2002

. NBR 6028: informação e documentação: resumo: apresentação. Rio de Janeiro, 2003.

. NBR 14724: informação e documentação: trabalhos acadêmicos:

apresentação. Rio de Janeiro, 2006.

. NBR 10520: informação e documentação: citações em documentos:

apresentação. Rio de Janeiro, 2002.

ARANHA, Maria Lúcia de Arruda; MARTINS, Maria Helena Pires. Filosofando: Introdução à filosofia. 3.ed. São Paulo: Moderna, 2003.

BORGES, Maria Alice Guimarães. A compreensão da sociedade da informação. Ciência da Informação, Brasília, v.29, n.3, p.25-32, set./dez. 2000.

BRASIL. Ministério da Ciência e Tecnologia. Sociedade da informação no Brasil: Livro Verde. Setembro, 2000. Disponível em:

<http://www.socinfo.org.br/livro_verde/download.htm>. Acesso em: 20 jun. 2009.

BRASIL. Ministério do Planejamento, Orçamento e Gestão. Instituto Brasileiro de Geografia e Estatística. PNAD 2009: rendimento e número de trabalhadores com carteira assinada sobem e desocupação aumenta. 2010. Disponível em: <http://www.ibge.gov.br/home/default.php>. Acesso em: 02 out. 2010.

BRASIL. Ministério do Trabalho. Classificação Brasileira de Ocupações. 2002.

Disponível em: <http://www.mtecbo.gov.br./busca/condicoes.asp?codigo=2612>. Acesso em: 20 set. 2010.

CAMPOS, A. M. F.; HOKAYEN-DA-SILVA, A. J.; ROSVADOSKI, P. Gestão por competência: classificação de competências em uma organização. In: CONGRESSO INTERNACIONAL DE ADMINISTRAÇÃO, GESTÃO ESTRATÉGICA NA ERA DO CONHECIMENTO, 2008, Ponta Grossa. Disponível em:

<http://www.admpg.com.br/2008/index.php?page=3\&lang=1\&sub=9>. Acesso em: 10 maio 2009. 
CERQUINHO, F. Z. Ética e qualidade: elementos para repensar a empresa. Disponível: $<$ http://www.abepro.org.br/biblioteca/ENEGEP1997_T4104.PDF>. Acesso em: 22 jun. 2009.

CONSELHO REGIONAL DE BIBLIOTECONOMIA 1a REGIÃO. Código de ética. Disponível em: <http://www.crb1.org.br/legislacao/codigo-de-etica.htm>. Acesso em: 15 jun. 2009.

FARIA, Sueli et al. Competências do profissional da informação: uma reflexão a partir da Classificação Brasileira de Ocupações. Ciência da Informação, v.34, n.2, p.26-33, maio/ago. 2005.

FARIAS, C. M.; CUNHA, M. V. da. O bibliotecário escolar e suas competências. Informação \& Sociedade, João Pessoa, v. 19, n.1, p.29-35, jan./abr. 2009.

FERNANDÉZ-MOLINA, J. C. Los aspectos éticos en la formación de los profesionales de la información. Disponível em:

$<$ http://www.ucm.es/info/multidoc/publicaciones/journal/pdf/aspectos-eticos.pdf>. Acesso em: 13 jun. 2009.

FERREIRA, Danielle Thiago. Profissional da informação: perfil de habilidades demandadas pelo mercado de trabalho. Ciência da Informação, Brasília, v.32, n.1, p.42-49, jan./abr. 2003.

FREIRE, José Eduardo et al. Competência na atual sociedade da informação. Disponível em: <http://www.abepro.org.br/biblioteca/ENEGEP2001_TR91_0981.pdf>. Acesso em: 6 jun. 2009.

GARVIN, David A. Gerenciando a qualidade. Rio de Janeiro: Qualitymark, 1992. 357p.

GOMES FILHO, Antônio Costa. Qualidade: momentos de verdade no serviço de atendimento aos usuários. In: SEMINÁRIO NACIONAL DE BIBLIOTECAS UNIVERSITÁRIAS, 12, 2002. Anais... Recife: UFPE, 2002. 15 p. Disponível em: <http://www.sibi.ufrj.br/snbu/snbu2002/oralpdf/18.a.pdf>. Acesso em: 25 maio 2009.

JAMBEIRO, O.; SILVA, H. P. da. A informação e suas profissões: a sobrivência ao alcance de todos. DataGramaZero: Revista de Ciência da Informação, v.5, n.4, ago. 2004. Disponível em: <http://www.dgz.org.br/ago04/Art_03.htm>. Acesso em: 17 maio 2009.

LITTON, Gaston. Arte y ciencia del bibliotecario. Buenos Aires: Bowker, 1970. 205 p.

MARCHIORI, P. Z.; PACHECO, M. R. L. Integração dos profissionais de informação: o futuro em sinergia. Informação e Informação, Londrina, v.2, n.2, p. 55-58, jul./dez., 1997. 
MIRANDA, Silvânia Vieira. Identificando competências informacionais. Ciência da Informação, Brasília, v. 33, n. 2, p. 112-122, maio/ago. 2004.

.Como as necessidades de informação podem se relacionar com as competências informacionais. Ciência da Informação, Brasília, v. 35, n. 3, p. 99-114, set./dez. 2006.

- Identificação de necessidades de informação e sua relação com competências informacionais: o caso da supervisão indireta de instituições financeiras no Brasil. 2007. Tese (Doutorado em Ciência da Informação)- Universidade de Brasília, Brasília, 2007.

MISCHIATI, A. C.; VALENTIM, M. L. P. Reflexões sobre a ética e a atuação profissional do bibliotecário. Transinformação, Campinas, v. 17, n. 3, p. 209-220, set./dez. 2005.

MUELLER, Suzana Pinheiro Machado. Uma profissão em evolução: profissionais da informação no Brasil sob a ótica de Abbott: proposta de estudo. In: BAPTISTA, S. G.; MUELLER, S. P. M. (organizadoras). Profissional da Informação: o espaço de trabalho. Brasília: Thesaurus, 2004. 241 p.

ORTEGA Y GASSET, José. Missão do bibliotecário. Brasília: Briquet de Lemos, 2006.

RASCHE, Francisca. Ética em bibliotecas públicas: representações de ética de profissionais da informação e bibliotecários. 2005. 280f. Dissertação (Mestrado em Ciência da Informação)-Programa de Pós-Graduação em Ciência da Informação, Universidade Federal de Santa Catarina, Florianópolis, 2005.

RIOS, T. A. Ética e competência. 6.ed. São Paulo: Cortez, 1997. 86 p.

SÁ, Antônio Lopes de. Ética profissional. São Paulo: Atlas, 1996. 193 p.

SANTOS, P. L. V. A. da C.; CARVALHO, A. M. G. de. Sociedade da informação: avanços e retrocessos no acesso e no uso da Informação. Informação \& Sociedade, João Pessoa, v.19, n.1, p. 45-55, jan./abr. 2009.

SERTEK, Paulo. Ética e qualidade nas organizações. Disponível em:

<http://www.demc.ufmg.br/gestao/E06.pdf>. Acesso em: 22 maio 2009.

SILVA, Germana Laura Helena da Silva. As dimensões da qualidade nos serviços da Biblioteca Setorial do DEP. João Pessoa, 2002. 58 p. Monografia (Especialização em Gestão da Qualidade e Produtividade)-Universidade Federal da Paraíba, João Pessoa, 2002. Disponível em:

<http://www.biblioteca.sebrae.com.br/bds/BDS.nsf/63066F8C12B99CC203256FE7004 11DBB/\$File/NT000A69AE.pdf>. Acesso em: 15 jun. 2009. 
SILVA, Luciana Candida da. Competências essenciais exigidas do bibliotecário frente aos desafios da sociedade da informação: um estudo dos profissionais de Goiânia-GO. 2009. 248 f. Dissertação (Mestrado em Ciência da Informação) -Universidade de Brasília, Brasília, 2009.

SILVA, M. A. P. D.; SILVA, E. M. A qualidade total e a ética: relações concretas e imaginárias. Acta Paul. Enf., v.12, n.3, p. 59-63, set./dez. 1999.

SUAIDEN, Emir José. Gestão e qualidade em serviços de informação no contexto das instituições públicas, 2006. Disponível em:

<http://www.cnen.gov.br/hs_Forum_Quali_Gestao/palestras/suaiden_ibict.pdf>. Acesso em: 20 maio 2009.

VITORINO, E. V. Competência informacional do profissional da Informação bibliotecário: construção social da realidade. Encontros Bibli, Florianópolis, n. 24, p. 5971, jul./dez. 2007. 